\title{
Transient ischemic attack presenting as recurrent migratory numbness by seconds: a rare case confirmed by transcranial Doppler micro-emboli monitoring
}

\author{
Xianyue Liu, Ke Han, Mingyi Hu, Huanquan Liao and Qinghua Hou* (B)
}

\begin{abstract}
Background: Transient ischemic attack (TIA) is a brief episode of cerebral ischemia. However, if a symptom is not presented as drop attack or hemiplegia, and alarming to the patient and the physician, how short of a symptom duration would raise the concern of a physician for TIA? It will be more complicated if the location of the neurological deficit is vagrant. This report highlights a rare TIA case which presented a very short duration of migratory patchy distribution numbness.

Case presentation: A middle-aged gentleman was presented with recurrent patchy distribution numbness on the right side of the body for 2 months, with the episode lasting as short as about $10 \mathrm{~s}$. The location of the numbness was erratic and migratory. Magnetic resonance angiography (MRA) revealed mild stenosis on the left middle cerebral artery (MCA). Transcranial Doppler (TCD) micro-emboli monitoring detected positive micro-emboli signals (MES), leading to the confirmation of a TIA diagnosis. After a standard dual antiplatelet treatment combined with enhanced lipid reduction therapy with statins, MES disappeared on dynamic TCD emboli monitoring, and no more episodes of TIA have been noticed on the follow-ups.

Conclusion: TIA caused by micro-emboli can display as recurrent migratory neurological deficit within seconds. TCD micro-emboli monitoring is very helpful to differentiate this situation from TIA mimics with follow-ups, as well as to locate unstable plague.
\end{abstract}

Keywords: Transient ischemic attack, Transcranial Doppler, Micro-embolic signals, Migratory numbness, Case report

\section{Background}

TIA is a transient episode of neurological dysfunction caused by focal brain, spinal cord, or retinal ischemia, without acute infarction [1]. The symptom of a typical TIA case will vanish most likely within $1 \mathrm{~h}$ [2], usually 5 to 15 mins [3], but rare in several seconds. If the symptom duration is as short as usually unconsidered seconds and the location of the neurological deficit is vagrant,

\footnotetext{
* Correspondence: hqhua_1976@163.com

The Clinical Neuroscience Center, The Seventh Affiliated Hospital, Sun Yat-sen University, Shenzhen 518107, China
}

the diagnosis of TIA is difficult to be established. We here report a rare case of TIA with repeated, migratory, rapidly-disappeared patchy distribution of numbness on one side of the body, which is confirmed by TCD microemboli monitoring.

\section{Case presentation}

A 44-year-old man, accounting himself to be basically healthy except for smoking for more than 20 years, presented in the clinic. The major complaint of this gentleman for this visit is that he has continually experienced

(c) The Author(s). 2020, corrected publication 2020. Open Access This article is licensed under a Creative Commons Attribution 4.0 International License, which permits use, sharing, adaptation, distribution and reproduction in any medium or format, as long as you give appropriate credit to the original author(s) and the source, provide a link to the Creative Commons licence, and indicate if changes were made. The images or other third party material in this article are included in the article's Creative Commons licence, unless indicated otherwise in a credit line to the material. If material is not included in the article's Creative Commons licence and your intended use is not permitted by statutory regulation or exceeds the permitted use, you will need to obtain permission directly from the copyright holder. To view a copy of this licence, visit http://creativecommons.org/ licenses/by/4.0/. The Creative Commons Public Domain Dedication waiver (http://creativecommons.org/publicdomain/zero/1. 0/) applies to the data made available in this article, unless otherwise stated in a credit line to the data. 
"recurrent numbness on the right side" in the past 2 months. The paroxysmal numbness is patchy, without weakness of the limbs, slurred speech and skewed mouth. The symptoms lasted only about 10 to $30 \mathrm{~s}$. The frequency of the symptoms varied from once a week to 6 times a day. The distribution of the numbness is erratic, mostly within the upper extremity, followed by the distal part of the lower extremity, and the least on the trunk, but all on the right side of the body. Through careful medical history interrogation, we found out that 2 years ago, this gentleman had manifested a symptom of inflexible right hand during a Mahjong playing, which lasted for about 5 mins and resolved totally. A similar inflexible right-hand symptom had recurred 3 times in the most recent 2 months. Furthermore, this man noticed an elevated fasting blood glucose on a physical examination performed 8 months prior to admission, but he did not take any pertinent measures to improve it except for the recent weeks' intake of metformin. These findings lead to the admission of this patient.

On admission, physical examination found no obvious abnormalities except for his obesity with a Body Mass Index (BMI) of $28.2 \mathrm{~kg} / \mathrm{m}^{2}$. Lab investigation only found mild-elevated serum lipids (TC $5.20 \mathrm{mmol} / \mathrm{L}$, TG 3.04 $\mathrm{mmol} / \mathrm{L}$, LDL-C $2.85 \mathrm{mmol} / \mathrm{L}$ ) and hyperglycemia (a fasting blood glucose of $7.56 \mathrm{mmol} / \mathrm{L}$ and a $\mathrm{HbA1C}$ of $7.1 \%)$.

Auxiliary investigations showed that 24-hrs electrocardiogram (ECG), color echocardiography, electromyography (EMG) and electroencephalogram (EEG) were all normal. A single flat plaque was detected on the right subclavian artery on carotid ultrasound. MRI-Brain diffusion weighted imaging (DWI) indicated multiple spotted hyperintensities within the left prefrontal cortex and centrum semiovale (Fig. 1), suggesting recent multifocal diffusion-restricted lesion caused by artery-to-artery embolism (corresponding to the upper extremity area of the precentral gyrus, which is highly consistent with the 3 times of inflexible hand symptom that had happened within the past 2 months). MRA showed mild focal stenosis at the horizontal segment of left MCA (Fig. 1), which is quite un-conspicuous.

TCD showed that a much-increased blood flow velocity was detected at left MCA and left anterior cerebral artery (ACA) $(142 \mathrm{~cm} / \mathrm{s}$ and $147 \mathrm{~cm} / \mathrm{s}$, respectively) with distorted spectral waveforms, indicating mild focal stenosis at these two arteries.

A dual-channel, dual-depth TCD micro-emboli monitoring protocol was applied, and the sample volume was set as $10 \mathrm{~mm}$ all through. At a depth of $54-64 \mathrm{~mm}, 4$ MES were detected at left MCA within a 30 mins time duration. At a depth of 52-63 mm at right MCA and a depth of $70 \mathrm{~mm}$ at left ACA, no MES were detected within 30 mins (Fig. 2). A double-check monitoring was conducted, and 6 MES were detected at left MCA within 30 mins. Again, no MES were detected at right MCA and left ACA.

The diagnosis was then established as clinical TIA with diffusion-restricted lesion and type 2 diabetes mellitus. Aspirin $100 \mathrm{mg}$ q.d., clopidogrel $75 \mathrm{mg}$ q.d., atorvastatin $40 \mathrm{mg}$ q.n., and blood glucose control therapy were then given to the patient, followed by a series of TCD micro-emboli monitoring to evaluate the effect. After just 2 days of treatment, the number of detected MES decreased to 2 on the 30 mins continuous monitoring, and with zero at the serial TCD monitoring at 3 days, 5 days and 3 months after treatment. A follow-up of clinical symptoms lasting for 1 year was also negative.

\section{Discussion and conclusion}

The diagnosis of TIA can be very challenging. In the evolutionary definition of TIA, though the duration limitation of symptoms of $<24 \mathrm{hrs}$ remains, the advances of imaging techniques is continuously cutting short the time duration needed to cause an ischemic lesion and tend to identify more and more ischemic strokes from a clinically defined TIA [4]. However, in making the diagnosis of TIA other than a TIA mimic, the most could be relied on is still, with no doubt, clinical symptoms [5]. Although scoring indicators integrated with medical

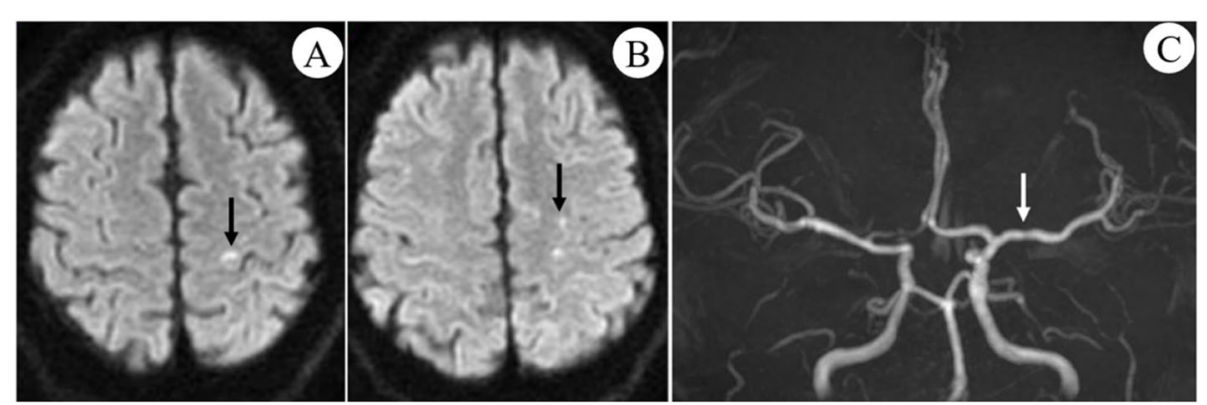

Fig. $1 \mathrm{MRI}-\mathrm{DW}$ and MRA findings. a, b multiple high signals on DWI located within the left prefrontal cortex and centrum semiovale (black arrows); c MRA showed mild focal stenosis on the LMCA horizontal segment (white arrow) 


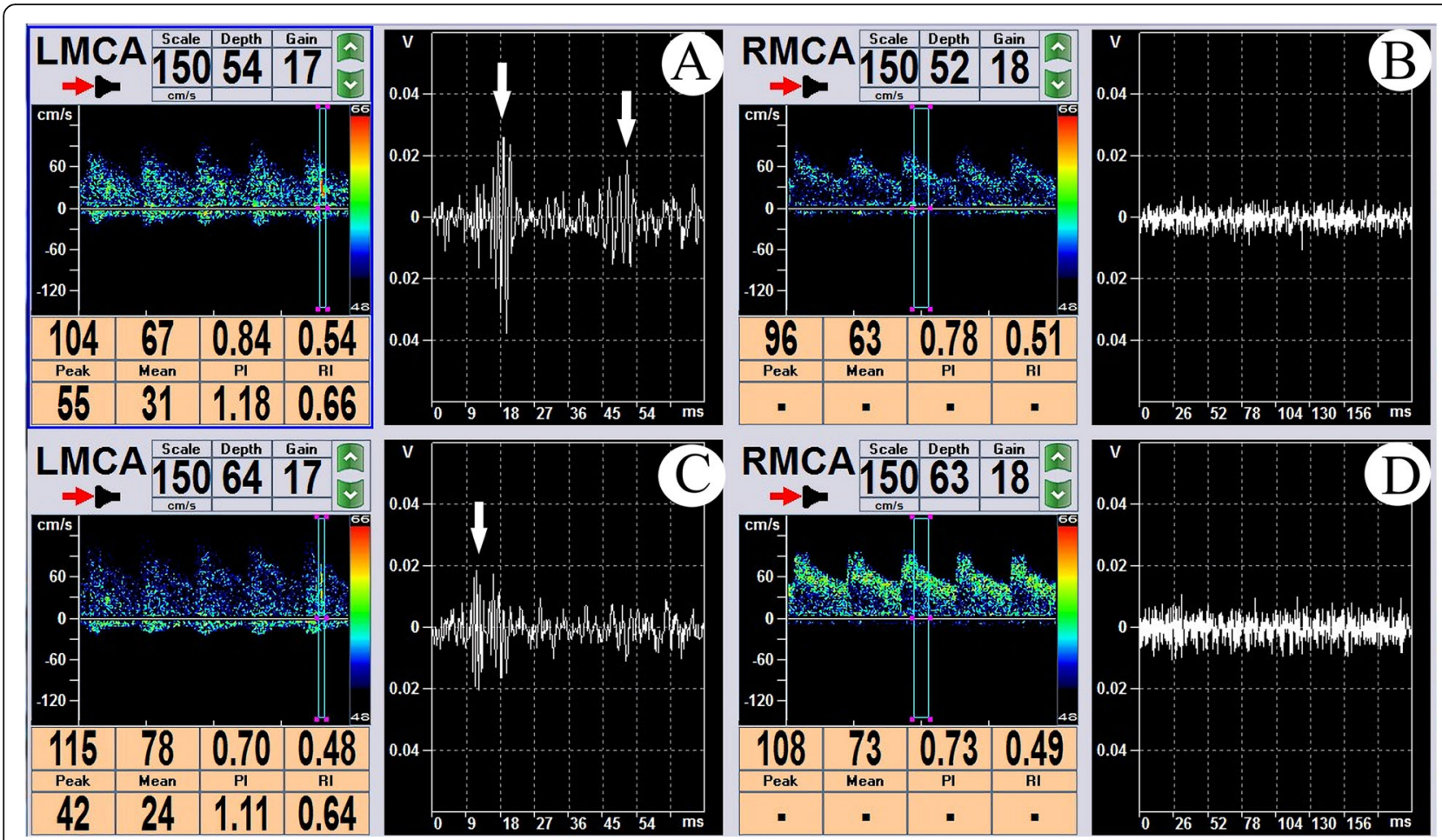

Fig. 2 Dual-channel, dual-depth TCD emboli monitoring. a, c TCD emboli monitoring of LMCA at a depth of $54 \mathrm{~cm}(\mathbf{a})$ and $64 \mathrm{~cm}$ (c), white arrows indicating the MES. It could be seen that the emboli was first detected at the depth of $64 \mathrm{~cm}$, and then moved toward the distal end of the blood vessel and was broken into two at the depth of $54 \mathrm{~cm}$. b, d No MES were observed at RMCA either at the depth of $52 \mathrm{~cm}(\mathbf{b})$ or of at the depth of $63 \mathrm{~cm}(\mathbf{d})$

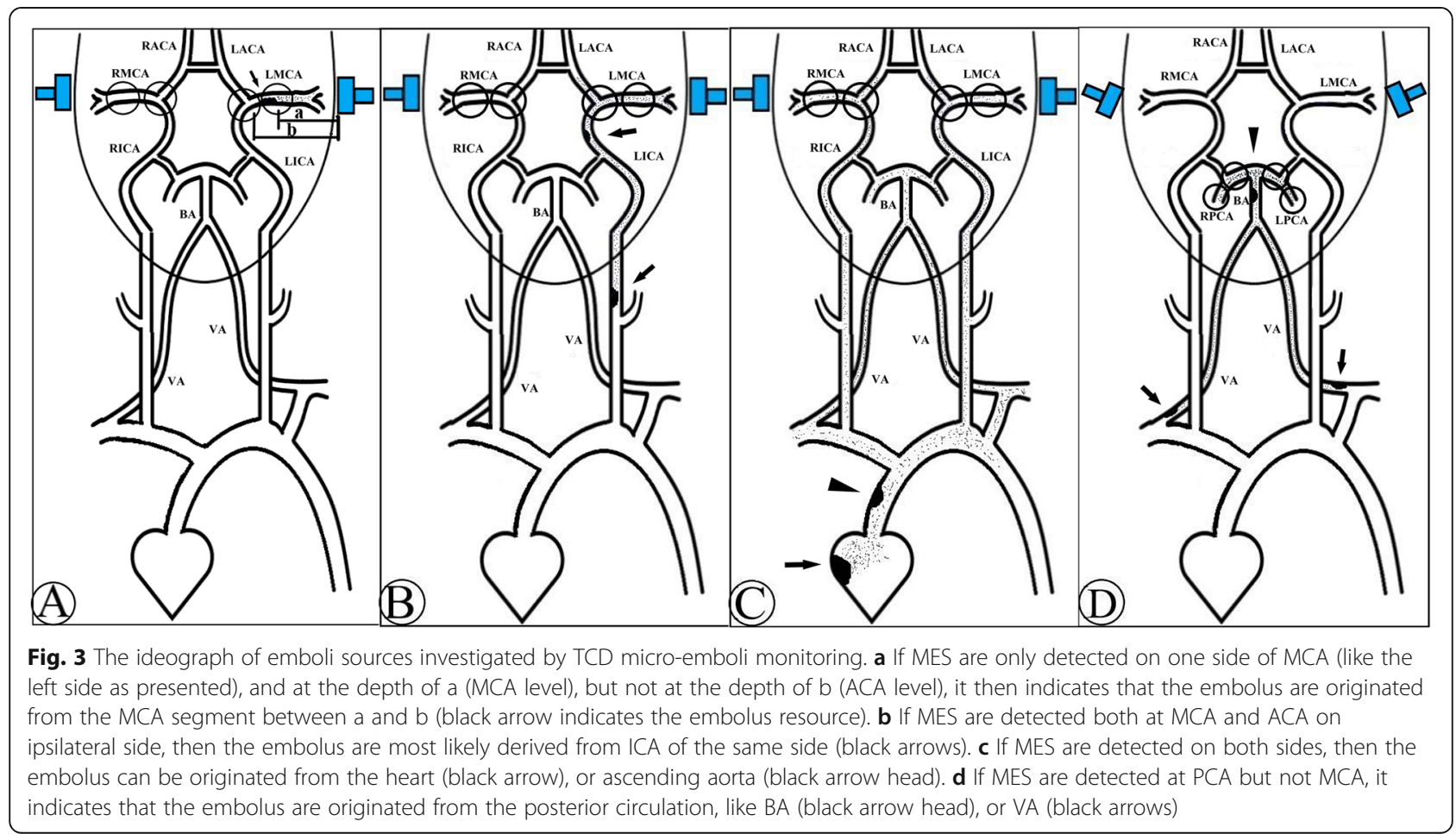


history, vascular events and risk factors have been developed to increase the accuracy of diagnosis of TIA [6], there is poor diagnostic agreement even among experts [7]. As for how long a symptom duration is long enough to raise the concern of the referred physician for TIA, no study has been conducted among neurologists, let alone among general practitioners. In a recent study, Counts et al. [8] pooled international multicenter cohort study of 1028 patients with lower risk transient or minor symptoms, and found out that $11.9 \%$ of patients had a symptom duration $<5$ mins, suggesting a short duration of symptom is not that rare in clinical practice. But what if the symptom duration is as short as counting in seconds, especially when symptoms presented are not those classified as "higher risk", such as dyskinesia or aphasia [9], like the patchy numbness manifested in the present case, and/or in an erratic migratory manner? And what if the symptoms have emerged less frequently than the present case? Will the chance be big that it will be neglected by general practitioners, and even by neurologists as well? This case has really enriched our knowledge of TIA.

When a TIA is suspected, and the structural basis of hypoperfusion mechanism is lacking, it is then reasonable to turn to the micro-embolism mechanism. In the present case, the MES are detected only on the left side during the bilaterally monitoring, which indicates the possibility of cardiac original embolus is low. Furthermore, it can be determined that the emboli are originated from the horizontal section of left MCA rather than elsewhere, because MES are visible at a depth of 54-64 mm, but not at a depth of $70 \mathrm{~mm}$ where left ACA is branched from the internal carotid artery (ICA) terminal (for better illustrating how did we locate different embolic sources, we drew a series of ideograph of TCD micro-emboli monitoring as Fig. 3) [10]. This is further reconfirmed by the DWI-positive lesions presented only in the territory of left MCA, and the un-conspicuous mild stenosis of left MCA detected by MRA and TCD.

In summary, our case shows that TIA caused by micro-emboli can display as recurrent migratory neurological deficit by seconds, which deserves further attention. By using TCD emboli monitoring, we can not only differentiate this situation from TIA mimics, but also evaluate the effect of treatment, and what's more, the location of unstable plaque that produces emboli can be determined. Of note, the failure to perform a highresolution MRI analysis of the plaque composition of the criminal vessel wall is a drawback.

\section{Abbreviations}

TIA: Transient ischemic attack; MRA: Magnetic resonance angiography; MRI: Magnetic resonance imaging; DWl: Diffusion weighted imaging; TCD: Transcranial Doppler; MES: Micro-emboli signals; BMI: Body Mass Index;
TC: Total cholesterol; TG: Triglyceride; LDL-C: Low-density lipoproteincholesterol; HbA1C: Hemoglobin A1C; ICA: Internal carotid artery; VA: Vertebral artery; BA: Basilar artery; MCA: Middle cerebral artery; ACA: Anterior cerebral artery; PCA: Posterior cerebral artery; L: Left; R: Right

\section{Acknowledgements}

Not applicable.

\section{Authors' contributions}

$\mathrm{QHH}, \mathrm{XYL}$ and $\mathrm{HQL}$ diagnosed, treated and followed up the patient. $\mathrm{KH}$ and MYH conducted the TCD follow-ups. XYL and QHH drafted the first manuscript. QHH and $\mathrm{KH}$ revised the manuscript. All authors read and approved the final manuscript.

\section{Funding}

This work was supported by the Sanming Project of Medicine in Shenzhen (SZSM201911003).

\section{Availability of data and materials}

All data related to this case report are contained within the manuscript and available from the corresponding author on reasonable request.

\section{Ethics approval and consent to participate}

Proved by the Human Investigation Committee and Institutional Review Board of the 7th Affiliated Hospital, SYSU.

\section{Consent for publication}

Written informed consent was obtained from the patient for publication of this case report and any involved images. A copy of the written consent is available for review by the editor of this journal.

\section{Competing interests}

All authors declare no competing interests.

Received: 21 July 2020 Accepted: 8 October 2020

Published online: 23 November 2020

\section{References}

1. Easton JD, Saver JL, Albers GW, Alberts MJ, Chaturvedi S, Feldmann E, Hatsukami TS, Higashida RT, Johnston SC, Kidwell CS, Lutsep HL, Miller E, Sacco RL, American Heart Association; American Stroke Association Stroke Council; Council on Cardiovascular Surgery and Anesthesia; Council on Cardiovascular Radiology and Intervention; Council on Cardiovascular Nursing; Interdisciplinary Council on Peripheral Vascular Disease. Definition and evaluation of transient ischemic attack: a scientific statement for healthcare professionals from the American Heart Association/American Stroke Association Stroke Council; Council on Cardiovascular Surgery and Anesthesia; Council on Cardiovascular Radiology and Intervention; Council on Cardiovascular Nursing; and the Interdisciplinary Council on Peripheral Vascular Disease. The American Academy of Neurology affirms the value of this statement as an educational tool for neurologists. Stroke. 2009;40(6): 2276-93. https://doi.org/10.1161/STROKEAHA.108.192218.

2. Albers GW, Caplan LR, Easton JD, et al. Transient ischemic attack-proposal for a new definition. N Engl J Med. 2002;347(21):1713-6.

3. Mohr JP. History of transient ischemic attack definition. Front Neurol Neurosci. 2014;33:1-10.

4. Wong KS, Caplan LR, Lim JS. Stroke mechanisms. Front Neurol Neurosci. 2016;40:58-71.

5. Fitzpatrick T, Gocan S, Wang CQ, Hamel C, Bourgoin A, Dowlatshahi D, Stotts $G$, Shamy M. How do neurologists diagnose transient ischemic attack: a systemic review. Int J Stroke. 2019;14(2):115-24. https://doi.org/10.1177/ 1747493018816430

6. Dolmans LS, Lebedeva ER, Veluponnar D, van Dijk EJ, Nederkoorn PJ, Hoes AW, Rutten FH, Olesen J, Kappelle LJ, MIND-TIA Study Group. Diagnostic accuracy of the explicit diagnostic criteria for transient ischemic attack: a validation study. Stroke. 2019;50(8):2080-5. https://doi.org/10.1161/ STROKEAHA.119.025626.

7. Castle J, Mlynash M, Lee K, Caulfield AF, Wolfford C, Kemp S, Hamilton S, Albers GW, Olivot JM. Agreement regarding diagnosis of transient ischemic attack fairly low among stroke-trained neurologists. Stroke. 2010;41(7):136770. https://doi.org/10.1161/STROKEAHA.109.577650. 
8. Coutts SB, Moreau F, Asdaghi N, Boulanger JM, Camden MC, Campbell BCV, Demchuk AM, Field TS, Goyal M, Krause M, Mandzia J, Menon BK, Mikulik R, Penn AM, Swartz RH, Hill MD. Diagnosis of uncertain-origin benign transient neurological symptoms (DOUBT) study group. Rate and prognosis of brain ischemia in patients with lower-risk transient or persistent minor neurologic events. JAMA Neurol. 2019. doi: https://doi.org/10.1001/jamaneurol.2019. 3063.

9. Lodha N, Patel P, Harrell J, Casamento-Moran A, Zablocki V, Christou EA, Poisson SN. Motor impairments in transient ischemic attack increase the odds of a positive diffusion-weighted imaging: a meta-analysis. Restor Neurol Neurosci. 2019;37(5):509-21. https://doi.org/10.3233/RNN-190940.

10. Gao S, Wong KS. Transcranial Doppler (TCD) ultrasound diagnostic technique and clinical application. Beijing: Peking Union Medical College Press; 2004. p. 319-26.

\section{Publisher's Note}

Springer Nature remains neutral with regard to jurisdictional claims in published maps and institutional affiliations.

Ready to submit your research? Choose BMC and benefit from:

- fast, convenient online submission

- thorough peer review by experienced researchers in your field

- rapid publication on acceptance

- support for research data, including large and complex data types

- gold Open Access which fosters wider collaboration and increased citations

- maximum visibility for your research: over $100 \mathrm{M}$ website views per year

At $\mathrm{BMC}$, research is always in progress.

Learn more biomedcentral.com/submissions 